\title{
VIVIR EL PATRIMONIO: JUAN TEMBOURY ÁLVAREZ (1899-1965). ENTRE LA CIENCIA TEÓRICA Y LA ERUDICIÓN
}

\author{
LIVING THE HERITAGE: JUAN TEMBOURY ALLAREZ (1899-1965). \\ BETWEEN THEORETICAL SCIENCE AND SCHOLARSHIP
}

CARLOS SARRIA FERNÁNDEZ

Universidad de Málaga (UMA)

Recibido: 20/02/2020

Aceptado: 27/04/2020

\section{RESUMEN}

Juan Temboury Álvarez fue un hombre poliédrico que trabajó siempre por y para la defensa del Patrimonio, la Cultura y el Arte. Estaba destinado a ser un miembro más de la indocta burguesía comercial malagueña a la que pertenecía, pero diversas circunstancias lo pusieron en el camino de interesarse por el Patrimonio. Posiblemente comenzase su andadura como lo haría un señorito diletante, pero, si así fue, eso debió durar poco tiempo, su compromiso con el Patrimonio y el Arte se fue haciendo cada vez más fuerte y aunque nunca fue su medio de vida, si fue su eje de actuación vital.

Palabras clave: Patrimonio, Juan Temboury, Catálogos, Málaga.

\section{ABSTRACT}

Juan Temboury Álvarez was a many-sided man who always worked for the defense of heritage, culture and art. He was destined to be one more member of the minimally educated Malaga commercial bourgeoisie to which he belonged, but various circumstances put him in the way of becoming interested in Heritage. Possibly he began 
his journey as an amateur. If so, that should have lasted a short time. His commitment to Heritage and Art, was becoming stronger and although it was never his livelihood, it was the centre of his vital action.

Keywords: Heritage, Temboury, Catalogs, Málaga.

Desde sus primeros pasos en el camino de la cultura y el arte, Juan Temboury Álvarez siempre se interesó principalmente por la conservación del Patrimonio histórico-artístico que heredamos. Siempre fue un patrimonialista, incluso antes de tener conciencia de que lo era. Por ello, desde sus comienzos, estuvo convencido de que la mejor defensa del Patrimonio era la catalogación de los bienes a preservar. Hasta tal punto lo consideró importante que convirtió dicha catalogación en el eje central de su trabajo y su defensa como existencia vital. Aunque su pronta muerte le impidió ver publicado el Catálogo Históricoartístico de la Provincia de Málaga en el que trabajaba cuando esta le sorprendió, dejó como herencia un gran número de intervenciones con las que consiguió invertir el ruinoso destino de muchos bienes. Igualmente se le puede anotar en su haber que con la publicación de algunos de sus trabajos se consiguiese la protección legal de bienes que hasta ese momento carecían de ella.

Temboury había comenzado a dar sus primeros pasos en el seno de la Sociedad Excursionista de Málaga y de la Sociedad Económica de Amigos del País de la mano del que fuese su primer mentor, Emilio Baeza Medina ${ }^{1}$. En este ambiente descubrió su pasión por el Patrimonio y su afición a la fotografía. En 1927 y durante su Viaje de Novios realizó una ruta iniciática al país del arte, Italia, donde recorrió Nápoles, Roma, Florencia, Asís y Venecia. En 1928 tuvo la oportunidad de coordinar la publicación que la Sociedad Económica de Amigos del País realizó con motivo del tercer centenario del nacimiento de Pedro de $\mathrm{Mena}^{2}$, durante este trabajo trabó amistad con el que sería su segundo y gran mentor Ricardo Orueta Duarte ${ }^{3}$.

1 Emilio Baeza Medina (Torrox 1892- Málaga 1980). Abogado. Perteneció a varios partidos de izquierda, siendo elegido concejal en dos legislaturas 1919 y 1931, durante la última fue elegido alcalde de Málaga el 14 de abril al proclamarse la II República; igualmente fue Diputado en Cortes durante dos legislaturas 1931 y 1936, durante la primera fue el líder de la minoría en el Congreso de Partido Republicano Radical Socialista.

2 VV.AA. Coord. TEMBOURY ÁlVAREZ, J. Pedro de Mena, escultor. Homenaje en su tercer centenario. Sociedad Económica de Amigos del País. Málaga. La impresión y maquetación fue realizada en la ya mítica "Imprenta Sur". 1928. Málaga.

3 Ricardo Orueta Duarte (Málaga 1868- Madrid 1939) Crítico e historiador del arte. En su juventud residió en Paris aprendiendo con Millet la técnica de la escultura, para la que tenía gran facilidad. 
En 1931 se produjo lo que podría calificarse como su «bautismo de fuego», nos referimos a los acontecimientos ocurridos en Málaga los días 11 y 12 de mayo cuando los incendios provocados por la turba destruyeron muchos edificios religiosos y con ellos multitud de objetos artísticos, algunos de un valor incalculable. Para Juan Temboury estos sucesos provocaron un efecto traumático que le condicionaría el resto de su vida para bien y para mal, ya que su evolución con respecto a otros hechos fue evidente al tiempo que cumplía años y adquiría experiencia, pero con respecto a los acontecimientos de mayo de 1931 mantuvo hasta el final de sus días el análisis que había realizado al calor de lo ocurrido, no admitiendo en su postura ninguno de los condicionantes que condujeron a tan desastrosa situación. Desde un punto de vista personal, Temboury vivió este episodio como un inactivo y dolorido «convidado de piedra» que iba asistiendo presencialmente a los incendios provocados sin poder intervenir en ninguno. Inmediatamente después su actitud fue la contraria, la de una persona activa que se encontraba, casi simultáneamente, en esos mismos lugares haciendo valoraciones de los daños producido en el patrimonio. Esta capacidad de respuesta, a partir de ese momento sería una de sus señas de identidad. En una carta que Salvador González Anaya ${ }^{4}$ dirigió a Ricardo Orueta el 17 de junio de $1931^{5}$, le dice:

La muerte del padre le forzó a volver a Málaga para hacerse cargo de su familia, lo que hizo durante varios años desde el desempeño de un trabajo administrativo. Durante los años de estancia en Málaga cursó por libre la carrera de Derecho en la Universidad de Granada. Igualmente durante esos años llegó al convencimiento de que aunque tenía facilidades para la escultura nunca sería un gran escultor, por lo que encaminó su amor al arte como crítico e historiador del mismo, especializándose en el estudio de las obras del escultor Pedro de Mena. Cuando pudo liberarse de las cargas familiares se trasladó a Madrid para continuar sus estudios de arte. En 1924 fue elegido miembro de la Academia de Bellas Artes de San Fernando. Comenzó a trabajar en el Centro de Estudios Históricos, dependiente de la Junta de Ampliación de Estudios. Allí conoció y trabajó, entre otros, junto a Manuel Gomez-Moreno. En Madrid fue miembro de la llamada Peña de los Malagueños, entre los que se encontraban José Moreno Villa, Alberto y Gustavo Giménez Fraud, Francisco Orueta y, aunque no era de Málaga, Manuel García Morente. Durante bastantes años vivió en la Residencia de Estudiantes de Madrid, donde coincidió y conoció a los miembros de la Generación del 27 que allí residían. En 1931 fue designado Director General de Bellas Artes en el gobierno de Manuel Hazaña, cargo que ejerció hasta diciembre de 1933. Bajo su dirección, en junio de 1931 se publicó el Decreto en el que se relacionan los monumentos históricos-artísticos de España a proteger por el Estado y en junio de 1933 la Ley sobre el Patrimonio Artístico Nacional. Entre 1934 y 1935 ocupó la Presidencia de la Junta Superior del Tesoro Artístico. En febrero de 1936 y con la victoria del Frente Popular es elegido de nuevo Director General de Bellas Artes, cargo que desempeñó hasta diciembre de 1936. Falleció en diciembre de 1939 en casa de su primo Francisco Orueta. Parte de estos datos han sido obtenidos de la Web de la Real Academia de la Historia el 11-11-2019.

4 Salvador González Anaya (Málaga 1879-1955). Comerciante, escritor y periodista. Ocupó en dos ocasiones el sillón de Alcalde de Málaga. Fue presidente de la Academia de Bellas Artes de San Telmo durante tres periodos ejerciendo el último hasta su fallecimiento. Parte de estos datos han sido obtenidos de la Web de la Real Academia de la Historia y de la de la de Bellas Artes de San Telmo el 1111-2019.

5 Carta de Salvador González Anaya a Ricardo Orueta del 17 de junio de 1931. Fuente: Legado Orueta, Biblioteca Tomás Navarro Tomás. 
"Juanito Temboury, que estuvo el domingo pasado gateando por las ruinas incendiadas del Palacio Obispal me asegura que, aunque no le ha sido posible entrar hasta el sitio, ha visto desde lo alto de unas vigas que la Biblioteca del Palacio se ha salvado milagrosamente de las ruinas y de las llamas, y buena parte del archivo, a juzgar por unas pilas ordenadas de legajos que se pudieron ver desde su distante y arriesgado observatorio. Allí deben estar los papeles de Medina Conde, que es una lástima que se hayan perdido".

El 9 de junio fue elegido miembro de la Academia de Bellas Artes de San Telmo $^{6}$, es decir casi simultáneamente a los hechos que hemos relatado, aunque ya había asistido como invitado a un pleno anterior ${ }^{7}$. En la primera reunión a la que asistió ya como académico, el 30 de octubre de ese año ${ }^{8}$, propuso: “...comenzar, de ser posible, el método de publicaciones de la Academia, iniciando el Catálogo Monumental de la Provincia, labor larga y fecunda para la que se autoriza una ponencia formada por los Sres. Anaya, Dumont y Temboury". Con esta propuesta acababa de poner la primera piedra de lo que él consideraba la columna vertebral de la protección del Patrimonio: la catalogación del mismo. Pero nunca se volvió a hablar en el seno de la Academia sobre esta iniciativa.

El segundo intento de Temboury en pro de la generación del catálogo se lo transmite a Ricardo Orueta en una carta que le envía 28 de abril de $1932^{9}$ en la que le dice:

"Hace tiempo que quero pedirle un favor que espero sabrá disculparme ya que sólo me guía al pedírselo hacer por la historia y el arte de Málaga una labor solo ahora posible y que habría de resultar muy útil en el mañana: quiero organizar en la Academia un fichero con fotografías lo más numerosas posibles de las cosas últimamente perdidas. Estas fotos tendrían una utilidad inmediata al tratar de restaurar o reponer aquello que pueda reconstruirse. Y en el futuro habría de ser el único modo de poder estudiar a los artistas locales. Este trabajo de recoger reproducciones es todavía posible por saberse más o menos quiénes las hicieron, pero pasado algún tiempo será imposible como ya lo es conseguir los archivos abundantes de Osuna y de Muchart ${ }^{10}$."

6 Acta de la Academia de Bellas Artes de San Telmo del 9 de junio de 1931. Vol. № 2 Fol. 77v. Academia de Bellas Artes de San Telmo.

$7 \quad$ Acta de la Academia de Bellas Artes de San Telmo del 14 de mayo de 1931. Vol. № 2 Fol. 75. Academia de Bellas Artes de San Telmo.

8 Acta de la Academia de Bellas Artes de San Telmo del 30 de octubre de 1931. Vol. No 2 Fol. 78v. Academia de Bellas Artes de San Telmo.

9 Carta de Juan Temboury a Ricardo Orueta del 28 de abril de 1932. Legado Orueta. Biblioteca Tomás Navarro Tomás.

10 Miguel Osuna Carnerero (activo entre 1875-1924) y Sabina Muchart Collboni (Olot 1838-Málaga 1929), fotógrafos. 
Temboury sigue persistiendo en su empeño y en vista de que su primer intento dentro de la Academia ha caído en saco roto, vuelve a intentarlo proponiéndo crear un archivo fotográfico en el seno de la Institución. Temboury es consciente de la afición de Orueta por la fotografía, además de constarle que había realizado bastantes en Málaga durante los años en que tuvo en ella su residencia:

"Sé que Vd. tiene hecho todo cuanto había en Málaga, bueno o mediano, en interiores, retablos y esculturas; son su labor diaria, callada romántica de su época malagueña. Algo de esto apareció en la "revelación" de Mena pero la mayor parte quedó inédito, desconocido de todos y hasta olvidado por Ud."

Pero también es consciente de lo reacio que es Orueta a prestar los negativos de sus fotografías:

"Quisiera que nos prestase los negativos de todo lo que tenga de Málaga aparte de lo de Mena por Vd. tan divulgado. Con ello llenaríamos el vacío más difícil de llenar, pues no hay casi nada de esto, que es precisamente lo más destrozado; sé muy bien en la estima que tiene y lo cuidadoso que es Ud. con sus negativos pero yo le prometo cuidárselos con toda atención y devolvérselos inmediatamente."

Orueta responde a la petición de Temboury el 4 de mayo ${ }^{11}$ :

"Recibo su carta y desde luego veo con simpatía su proyecto de fichero, para el que desde luego pondré a disposición de Vd. los cliché que me pide..."

No obstante aplaza en el tiempo el complacer la petición de Temboury:

“...pero de momento no me es posible hacerlo porque tengo repartidos y desordenados ${ }^{12}$ y para poder realizar una selección necesitaría u tiempo de que carezco en los momentos actuales. Cuando cese en este cargo [Director General de Bellas Artes] y me reintegre a mi vida del Centro de Estudios Históricos dedicaré unos días a preparar lo que Ud. me pide"

11 Carta de Ricardo Orueta a Juan Temboury del 4 de mayo de 1932. Legado Orueta. Biblioteca Tomás Navarro Tomás.

12 Efectivamente Ricardo Orueta tenía negativos en el Centro de Estudios Históricos, pero según nos relata José Moreno Villa en sus memorias Vida en claro, la habitación de Ricardo Orueta en la Residencia de Estudiantes, donde ambos residían, se encontraba en su totalidad cruzada por cordeles de donde colgaba las fotografias para secar y multitud de negativos y fotografias por todas partes. Los ejemplares que tenía en el Centro de Estudios se conservaron perfectamente y hoy forman parte del Legado Orueta, pero todo aquello que tenía en la Residencia debió perderse, porque cuando se trasladó desde la Residencia a casa de su primo Francisco Orueta fueron muy pocas las pertenencias que se llevó. 
Orueta fue cesado en su cargo en diciembre de 1933, pero el ofrecimiento nunca llegó a materializarse.

De nuevo en el seno de la Academia de Bellas Artes de San Telmo, en el pleno del 29 de abril de $1933^{13}$ el pintor Nogales Sevilla, por medio de una carta, solicita a la Academia que se preocupe por una serie de esculturas de gran valor (no especificadas). Los académicos deciden solicitar su inclusión en el Catálogo Artístico de España, para tal fin se decide formar una comisión compuesta por Marquina, Díaz de Escovar, Álvarez Dumont y Temboury. Comisión que como la anterior, a la que ya nos hemos referido, no tuvo ningún recorrido.

Como vemos, los intentos que hasta este momento había realizado Temboury para comenzar un catálogo del Patrimonio Histórico-artístico de Málaga siempre lo encuadraba como un trabajo colectivo, es de pensar que él no se encontrase en condiciones de afrontar solo tamaña empresa. No obstante, su archivo se iba incrementando con los resultados de todas las intervenciones que realizaba, con las fotografías que había ido acumulado desde sus inicios en la Sociedad Excursionista de Málaga; en definitiva con todo aquello que podía ir recopilando referente al patrimonio histórico-artístico de Málaga y su provincia. Pero pasarían bastantes años hasta que él se plantease acometer la elaboración del catálogo en solitario.

Sobre la Provincia de Málaga ya había un Catálogo Monumental que lo realizó Rodrigo Amador de los Ríos en 1907, pero la comisión que tenía que dar el visto bueno al mismo no lo consideró de suficiente calidad para ser publicado y quedó inédito. Juan Temboury no solo conocía estas circunstancias, sino que desde muy pronto consiguió hacerse con una copia del manuscrito que se había decidido no publicar. Temboury estaba totalmente de acuerdo con la baja calidad del mismo, y en aquellas ocasiones que tuvo la oportunidad de hablar de este catálogo siempre manifestó su opinión contraria al mismo, al que acusaba de no haber incluido muchos de los bienes que ya se conocían en la época en que Amador de los Ríos lo elaboró y los errores los basaba en la metodología seguida, ya, que según Temboury, el autor lo había elaborado en base a una encuesta que se había enviado a las personas principales de cada pueblo, en especial al cura de la localidad, y muchos de ellos no tenían el criterio suficiente para realizar ese catálogo ni una aproximación a la valoración históricoartística de los bienes. Temboury por el contrario sostenía que el catálogo había que hacerlo visitando cada localidad y elaborarlo con la ayuda de las

13 Acta de la Academia de Bellas Artes de San Telmo del 29 de abril de 1933. Academia de Bellas Artes de San Telmo. 
autoridades de la misma. Otra de las faltas que acusaba Temboury en trabajo de Amador de los Ríos era la falta de fotografías de los bienes inventariados.

Pero la labor patrimonialista de Temboury no solo se limitó a la elaboración de ese catálogo al que nos hemos ido refiriendo. Por el contrario su nómina de intervenciones en pro del Patrimonio de la Provincia de Málaga es enorme. El elaborar en este trabajo una relación exhaustiva de esas intervenciones además de interminable sería poco esclarecedor, por los que vamos a ir relatado de modo cronológico aquellas intervenciones que supusieron de algún modo hitos en la salvaguarda del Patrimonio y que lo hizo por distintos caminos: demostrando un valor en los mismos que les diese carácter de elemento a proteger, rehabilitando bienes deteriorados, sacando a la luz bienes demostrando su autoría, haciendo excavaciones de bienes enterrados, catalogación de bienes ya desaparecidos, incluso, conseguir el cambio de la legislación urbanística de unos bienes no protegidos a partir del estudio sobre los mismos.

$\mathrm{Si}$ obviamos las fotografías que realizaba durante salidas con la Sociedad Excursionista, su primera intervención importante se tradujo en la recuperación y catalogación de todos aquellos restos que quedaron en los edificios quemados durante los incidentes de mayo de 1931 y proteger aquellos que por intereses espurios se queríanhacer pasar por desaparecidos o destruidos ${ }^{14}$. Una de las gestiones más interesantes que realizó sobre las consecuencias de estos acontecimientos fue la de salvar, de entre los escombros, un buen número de los mosaicos de gran valor artístico que adornaban las galerías del destruido Palacio Obispal y que se volvieron a instalar una vez fue reconstruido el edificio. Igualmente tuvo la oportunidad de realizar varios informes sobre los bienes destruidos.

$\mathrm{Su}$ mentor Ricardo Orueta, otro gran patrimonialista, desde la Dirección General de Bellas Artes consiguió sacar adelante bastantes normativas sobre la protección del Patrimonio, pero de la que destacan dos disposiciones que supusieron un avance en esa interpretación y sirvieron de un ejemplo a aplicar en el resto de países europeos. Nos referimos al Decreto con la Declaración Monumentos Históricos Artísticos que se hizo con fecha 3 de junio de $1931^{15}$ y la

14 En una carta de Ricardo Orueta a Juan Temboury del 22 de agosto de 1931, le dice: “"'Yo le ruego que cuantas noticias tenga sobre obras de arte existentes en Málaga, sobre lo salvado y lo perdido de los incendios y sobre lo que se haya vendido, muy especialmente por elementos eclesiásticos;“. Legado Ricardo Orueta. Tomás Navarro Tomás.

Telegrama de José Carreño a Miguel Coloma Rubio, Gobernador Civil de Málaga del 27 de agosto de 1931.en el que le dice: "Noticias que parecen ciertas llegadas a esta Dirección dicen que de las iglesias de Vélez Málaga se están retirando objetos de arte. Ruego a V.E. investigue si es cierta la denuncia y en caso afirmativo adopte las medidas que estime pertinente para salvaguardar Tesoro Artístico Nacional". Legado Orueta. Biblioteca Tomás Navarro Tomás.

15 Gaceta de Madrid del 3 de junio de 1931. n 155, págs. 1181-1185. 
Ley sobre el Patrimonio Artístico Nacional del 13 de mayo de $1933^{16}$. La primera disposición fue un catálogo de bienes españoles a proteger, mientras que la segunda supuso la puesta en valor de una nueva concepción e interpretación del Patrimonio Histórico de la Nación ${ }^{17}$. Estas actuaciones de Orueta no hicieron sino acrecentar el interés por el Patrimonio que Temboury manifestaba, proyectando ese interés a una visión más contemporánea del concepto Patrimonio y su defensa. Esa avanzada interpretación de los bienes patrimoniales y las nuevas metodologías de conservación las mantendría hasta el final de sus días, aunque bien es cierto que atravesó épocas oscuras, de las que incluso él fue protagonista, en las que tuvo que callar sus puntos de vista.

Las dos normativas antes referidas, unidas a las primeras dotaciones presupuestarias dieron lugar al comienzo de su actuación en las obras de rehabilitación del Conjunto Monumental de la Alcazaba y Castillo de Gibralfaro, donde bajo la dirección de Leopoldo Torres Balbás y trabajando junto al arquitecto José González Edo, formaron un grupo que consiguió levantar, aparentemente de la nada, El Monumento que hoy disfrutamos. Su actuación en estas obras es, con toda seguridad, por lo que fue más conocido en Málaga. Actualmente la entrada del monumento está franqueada por una lápida que recuerda su actuación y el busto que de él realizase su amigo el escultor Adrián Risueño y donde el paseo que rodea la parte sur lleva su nombre. Es difícil valorar si fue esta empresa a la que le dedicó más trabajo, lo que sí es cierto que fue la que más se alargó más en el tiempo. Pero el verdadero valor que creemos se debe otorgar a la labor de Temboury sobre el Conjunto Monumental que ahora contemplamos es que sin su acción o acciones posiblemente hoy difícilmente lo disfrutaríamos. En una carta que Torres Balbás le dirige el 22 de julio de $1942^{18}$, transmite ese sentimiento:

"Parece milagroso que se hayan adquirido tantas fincas y faltan tan pocas para hacerse con el recinto de la Alcazaba. Si es milagro, a V. se le debe. No sé si en Málaga se han dado cuenta o se darán algún día de que V. es el padre y madre y hasta abuelo de esa Alcazaba surgida de un montón de escombros y basura. Los demás hemos sido nada más que acompañamiento. Si eso de las lápidas no estuviera tan desacreditado, habría que poner una a la entrada que dijese, poco más o menos «El rescate, la limpieza y urbanización de esta Alcazaba se deben al generoso entusiasmo de Luan Temboury»".

16 Gaceta de Madrid del 25 de mayo de 1933, nº 145, págs. 1394-1399

17 La Ley dice en su artículo 3: "Compete a la Dirección General de Bellas Artes cuanto atañe a la defensa, conservación y acrecentamiento del patrimonio histórico-artístico nacional.

18 Carta de Leopoldo Torres Balbás a Juan Temboury del 22 de julio de 1942. Legado Temboury. 
En el mes de marzo de 1936, una vez que Ricardo Orueta había sido elegido de nuevo para el puesto de Director General de Bellas Artes, este nombró a Temboury Delegado Provincial de Bellas Artes ${ }^{19}$, lo que de algún modo supuso oficializar las múltiples actuaciones que también realizaba en la Provincia, casi siempre junto con su amigo Simeón Giménez Reyna, como eran sus visitas a los yacimientos arqueológicos de San Pedro Alcántara, las ruinas de Acinipo en Ronda o la Cueva de la Pileta.

Desde su nombramiento, en marzo de 1936, Temboury tuvo pocas ocasiones de actuar en condiciones de normalidad, porque desde el Golpe de Estado la sucesión de acontecimientos generales y particulare ${ }^{20}$ le afectaron de modo muy significativo. No obstante en ningún momento dejó de trabajar, y es muy posible que lo hiciese a modo de terapia. En la Alcazaba él era el único responsable y tenía que seguir dándoles trabajo a los oficiales especialistas que Torres Balbás se había traído desde la Alhambra y que no podían volver a Granada porque esta ciudad se encontraba en poder de los rebeldes.

Otra importante actuación, muy trascendente, en la protección del Patrimonio fue la salvaguarda de la mayoría de los bienes de la Catedral cuando esta fue designada como alojamiento de los refugiados que huían de las tropas rebeldes. Para ello enclaustraron en las sacristías y el coro todos aquellos bienes que era posible trasladar, así como bienes procedentes de otros edificios religiosos como fue la imagen de la Virgen de la Victoria, luego cerraron con muros de ladrillos los referidos espacios. Continuando con su actuación en el edificio de la Catedral, cuando el 7 de febrero de 1937 las tropas rebeldes entraron en Málaga, asumió la responsabilidad de intentar llevar a un estado de normalidad el edificio catedralicio, ya que mientras sirvió de refugio se habían hecho en su interior fuegos, usándolo como cocinas e incluso como letrinas, dándose el caso que aquellos retablos, algunos de gran valor, que no pudieron trasladarse fueron usados como leña para el fuego con el intentaban combatir el frio los refugiados.

De estos terribles momentos hay que destacar una actuación de Juan Temboury que lo ennoblece, nos referimos a la defensa por escrito que realizó hasta

19 El desempeño por Juan Temboury del cargo de Delegado Provincial de Bellas Artes es el caso más singular que conocemos, ya que fue nombrado por el Gobierno de la República en 1936 y sin solución de continuidad no fue cesado ni refrendado en el puesto por el Gobierno nacido del Golpe de Estado Militar y siguió actuando como Delegado hasta su fallecimiento en 1965.

20 Durante los últimos días del mes de julio de 1936 fue asesinado por la espalda su hermano Pedro, sin que nunca se llegase a saber quién lo hizo, y su hermano Francisco fue detenido por las milicias republicanas. Además, el negocio familiar fue pasto de las llamas al igual que toda la manzana en la que se encontraba en la calle 14 de abril. 
en tres ocasiones a favor de los miembros de Junta de Defensa del Tesoro Artístico $^{21}$ y en especial de su presidente Vicente Andrade, no hay que olvidar que esa actuación la realizó en unos momentos en que iniciativas de este tipo arriesgaban la integridad personal. Existen otros casos muy próximos a Temboury en los que la forma de actuar fue la contraria, en concreto el equipo directivo en ese momento de la Academia de Bellas Artes de San Telmo acusó a la referida Junta de haber realizado un robo selectivo de documentos, hecho este en el que si se ahonda un poco se llega a la conclusión de que los documentos sustraídos implicaban a miembros de la Academia con actuaciones políticas durante el periodo republicano.

Entre 1937 y 1939 transcurre para Temboury una etapa oscura desde el punto de vista artístico, periodo que coincide con su paso por la política local dentro de la Comisión Gestora que se hizo cargo del Ayuntamiento de Málaga. No obstante en ese periodo que consideramos infértil le habían sido otorgados por parte del Gobernador Civil, García Alted, unos poderes casi omnímodos para controlar y recuperar todos aquellos bienes que hubiesen sido enajenados durante el "periodo rojo" 22 . No obstante, Temboury sí continuó trabajando en las obras de la Alcazaba junto con el Arquitecto Fernando Guerrero-Strachan Rosado, colaboración que duraría hasta 1941, fecha del fallecimiento de este último. Este periodo es coincidente con aquellas obras que han sido puestas más en cuestión desde un punto de vista historicista entre todas las obras llevadas a cabo en el Conjunto Monumental de la Alcazaba.

En 1941 el Obispo de la ciudad Balbino Santos Olivera convocó a Juan Temboury para que formara parte de la Junta Pro-Coronación de la imagen de

21 La Junta de Defensa del Tesoro Artístico en Málaga se debió crear a similitud de la Junta de Incautación y Protección del Patrimonio Artístico creada por un Decreto de 2 de agosto de 1936 y que se refería específicamente al ámbito de Madrid. Estas Juntas actuaron con mayor o menor fortuna en distintas ciudades, dependiendo del poder real que ejercían las autoridades oficiales. En Málaga, al parecer, tuvo una incidencia bastante importante, ya que pasados los primeros días de desconcierto y desorganización, la Junta consiguió evitar o conservar la mayoría de las incautaciones que se realizaban; de hecho cuando entraron las tropas rebeldes en la ciudad, las incautaciones realizadas (posiblemente no fuesen todas) se encontraban almacenadas en la sede de la Biblioteca Ricardo Orueta, existiendo un inventario de todo lo almacenado.

22 Con fecha 30 de febrero de 1937 el Gobernador Civil García Alted le envía un oficio con el siguiente texto:

"Teniendo en cuenta los conocimientos artísticos que V. posee, con esta fecha he tenido a bien, concederle amplias facultades para que nombre a los individuos que crea necesario y bajo su absoluta dirección, proceda a efectuar en esta Capital y pueblos su provincia, inventario de todo lo relacionado con Bellas Artes y Tesoro Artístico Nacional, quedando autorizado para poder trasladarse al lugar que convenga y penetrar en cuantas dependencias y domicilios crea necesario a los fines ya expresados; esperando de las fuerzas y agentes armados a mis órdenes guarden a dicho Sr. las consideraciones que el cargo para el que se le nombra merecen.

Dios guarde a España y a V. muchos años. Málaga a 30 de febrero de 1937

EL GOBERNADOR CIVIL 
la Virgen de la Victoria acto que habría de celebrarse en 1943. Y había que hacerlo a lo grande, incluso por encima de las posibilidades económicas del momento y que podríamos resumir en lo escrito por el Obispo en referencia a la riqueza y boato de la futura corona: "La nueva corona que con tan fausto motivo ha de ceñir las sienes de la Señora, tiene que ser riquísima por su materia, artística por su estructura y expresiva por su mismo simbolismo"23. Sería la oportunidad de quien, en palabras del profesor Sánchez López: “...con su acostumbrada y certera intuición, Juan Temboury afirmaba que la Virgen de la Victoria es la verdadera y única clave de todo el Santuario"24. Temboury se acercó a ese mundo que representaba la imagen de la Virgen de la Victoria como un todo indivisible que atesora y explica la historia de la Málaga cristiana en todas sus manifestaciones artísticas, sociales, religiosas, etc., a modo de reservorio donde se conserva un pequeño y completo testimonio de todo el Patrimonio, el conservado y el destruido, de los últimos cinco siglos de la historia de la Ciudad. Temboury, además, supo valorar que lo contenido en ese "universo Victoriano" traspasaba las fronteras de lo local para convertirse en una lectura sin interrupciones y polisémica de la intencionalidad y lo que representó el estilo barroco para la sociedad de su tiempo y más concretamente el barroco andaluz.

El catedrático Sánchez López comenta que Temboury fue el encargado de la supervisión y asesoría del producto final de la corona y el cetro para la imagen de la Virgen de la Victoria ${ }^{25}$. Temboury, con una visión muy certera, supo combinar el respeto a la antigüedad y origen de la imagen con la riqueza y lujo que del resultado se esperaba. Juan Antonio Sánchez deja claro que Temboury no se atuvo a un historicismo ortodoxo, si no que se remontó para la inspiración del estilo que debía llevar la corona a la que fue ceñida por Isabel I de Castilla y que se encuentra depositada en la Capilla Real de la Catedral de Granada, pero procurando que el resultado no fuese una copia exacta de la misma. En cuanto al cetro tuvo como referente el portado por la imagen de la Virgen de la Antigua que se encuentra en la Catedral de Granada. La otra vía principal que emprendió Juan Temboury fue la que en palabras del profesor Sánchez López supuso la repristinación de la imagen, que en este caso consistía

23 SANTOS OLIVERA, B. "La coronación canónica de Nuestra Señora de la Victoria", Málaga por la Virgen de la Victoria. Excmo. Ayuntamiento de Málaga. 1943. Málaga. Págs. 5-7.

24 SÁNCHEZ LÓPEZ, J.A. "«Esta es la victoria que vence al mundo». Pervivencia, transformación y memoria de una iconografia histórica", SPECVLVM SINE MACVLA Santa María de la Victoria, espejo histórico de la ciudad de Málaga. Excmo. Ayuntamiento de Málaga y Real Hermandad de Santa María de la Victoria. 2008. Málaga. Págs. 359-400.

25 Según las investigaciones llevadas a cabo por el profesor Sánchez López los diseños de la corona y el cetro fueron realizados por el padre Granda pero siempre bajo la inspiración y supervisión de Juan Temboury. 
principalmente en desnudar la imagen de los ropajes que durante varios siglos habían "adecentado y enriquecido" la desnudez de la madera, aunque las vestimentas ya estuviesen representadas en la propia escultura. Dentro de del proceso de repristinación Temboury incluyó el realizar una nueva imagen del Niño que se pudiese colocar en el regazo la escultura de la Virgen, ya que la anterior había sido articulada en brazos y piernas para poder sentarla en la silla a los pies de la imagen ${ }^{26}$. Para ello encargó a su amigo el escultor Adrián Risueño la talla del Niño, quien, aunque la tuvo que repetir a petición de Temboury, consiguió realizar posiblemente la que es una de las mejores esculturas de toda su obra. Igualmente Risueño fue el autor del pajarito que porta la Virgen actualmente en su mano izquierda.

Las intervenciones ya comentadas llevarían Temboury a la interesarse y poner en valor la decoración en yeso del Periodo Barroco Andaluz donde valora los magníficos trabajos que decoran la iglesia y camarín de la Victoria. Puede que Temboury fuese uno de los primeros investigadores, posteriores al siglo XIX, que comenzaron a darle valor artístico a lo que desde ese siglo se había considerado un arte menor, cuando no se le calificaba de mal gusto barroco. $\mathrm{Su}$ interés por la decoración en yeso le llevó a ampliar sus investigaciones a otras iglesias de Málaga y la Provincia de las que destacaban algunas de Antequera y Ronda, trabajo de investigación que plasmó en el artículo Para el estudio de la Arquitectura andaluza. La ornamentación en yeso a principios del siglo $X V I I I^{27}$. El texto es en sí mismo un ejemplo del mejor Temboury, donde el primero y último de los párrafos se encuentran perfectamente concatenados y en su conjunto supone una declaración de principios sobre lo que para Temboury significa el concepto de arte y en el que también reivindica esta forma artística, tan denostada desde finales del siglo XVIII y hasta principios del $\mathrm{XX}^{28}$ :

Primer párrafo:

"Uno de los temas más interesantes y menos estudiados en las historia del Arte Andaluz es el grupo de decoradores en yeso que cubre de delirantes

26 La anterior escultura del Niño se conserva en el pequeño museo que contiene el Santuario de Ntra. Señora de la Victoria.

27 TEMBOURY ALVAREZ J. "Para el estudio de la Arquitectura andaluza. La ornamentación en yeso a principios del siglo XVIII". Semanario El Sol de Antequera número extraordinario. Agosto de 1949. Antequera.

28 Narciso Díaz de Escovar en un artículo titulado Efemérides malagueñas. La capilla mayor de la Victoria, que se encuentra en el Legado Federico Muñoz y del que no consta el diario en el que se publicó ni la fecha, incluye la siguiente frase: "El camarín es rico, pero de mal gusto.". es evidente que la opinión de Díaz de Escovar, a pesar de ser contemporáneo de Juan Temboury, se encontraba todavía instalada en una estética decimonónica. 
ornamentaciones las bóvedas de nuestros templos, desde finales del siglo XVII hasta la mitad de la centuria siguiente."

Último párrafo:

"Es absurdo desdeñarlo por estar labrados en materia blanda y no definitiva. En arte, la genial inspiración fugaz, tiene más brío, espontaneidad y personalismo que la obra académica lentamente concebida. Por eso descubrimos más fácilmente el destello del alma creadora, en los «improntus», en los diseños y en los borroncillos de los pintores. El escultor mismo, ultima su obra en barro; el pasarlo a mármol o bronce es trabajo secundario que realizan vulgares operarios."

La intervención e investigación de Temboury en el Santuario de la Virgen de la Victoria no se limitaría a lo anteriormente descrito, su avance en la profundización del polisémico lenguaje barroco le llevaría a afrontar una posible interpretación unitaria de los distintos espacios que componen la torrecamarín del santuario. Es difícil llegar a saber por qué caminos llegó a su acertada lectura iconográfica, pero sí existen multitud de pruebas documentales en su Legado que demuestran que su búsqueda fue exhaustiva.

La torre-camarín se construyó a expensas del Conde de Buenavista, José Guerrero Chafarino, ideada por el monje mínimo Fray Alonso de Berlanga y construida entre 1693 y 1700 por el arquitecto Felipe de Unzurrúnzaga. La lectura que hizo Juan Temboury de este conjunto arquitectónico está basada en una interpretación de Los ejercicios Espirituales de San Ignacio de Loyola, y divide el conjunto arquitectónico en tres plantas: la cripta, un tétrico y cuadrado espacio terrenal donde se representa el «tempus fugit»; una segunda planta, en el que un espacio cuadrado, que conecta con la pared donde se encuentra el altar mayor de la iglesia y que representa a la Iglesia institución; para finalmente culminar en una tercera planta de forma octogonal que está presidido por la imagen de la Virgen de la Victoria y donde en un paroxismo de la decoración barroca están representados todos los atributos de la Madre de Dios, es el Paraíso. Las tres plantas están conectadas por una escalera de cuarenta y ocho escalones en seis tramos de ocho, número cristológico. El techo de la caja de la escalera es una bóveda esquifada que en el centro presenta la Imagen del Salvador del mundo y alrededor doce lunetos con un apóstol en cada uno de ellos y portando su símbolo de identificación. La interpretación iconográfica realizada por Temboury es la del camino que debe seguir el penitente desde el mortal mundo terrenal hasta alcanzar el Paraíso, lo que debe hacer por un esforzado y virtuoso camino, pero en el que siempre estará acompañado por la Iglesia Institución. 
Juan Temboury no llegó a publicar el manuscrito sobre la Torre-camarín, esto se hizo después de su muerte ${ }^{29}$, siendo difícil saber el por qué lo había mantenido inédito. Posteriores trabajos han vuelto a estudiar la lectura iconográfica del edificio, pero en lo esencial ninguno de ellos contradijo la interpretación realizada por Temboury. Asi el profesor Santiago Sebastián ${ }^{30}$ en su trabajo El Pía Desideria de Hermann Hugo y el Santuario de la Virgen de la Victoria: un ensayo de lectura, centra que la lectura de la torre-camarín está basada en la interpretación que de los Ejercicios Espirituales de San Ignacio de Loyola hizo el Jesuita Alemán Hermann Hugo en su libro El Pia Desideria. Años más tarde la catedrática Rosario Camacho volvió a retomar el estudio de este espacio arquitectónico en su trabajo La emblemática y la mística en el santuario de la Victoria en Málaga ${ }^{31}$, realizando en el mismo una convergencia de las interpretaciones de Temboury y de Sebastián, abundando especialmente en el estudio de los símbolos marianos del camarín de la Virgen. Ni que decir tiene que se debe considerar como una proeza el trabajo llevado a cabo por Juan Temboury, al sacar a la luz la interpretación de un espacio que el tiempo había conseguido enterrar, máxime si tenemos en cuenta que cuando Temboury comenzó su investigación, alrededor de 1950, la iconografía era una ciencia absolutamente desconocida en nuestro país.

A mediados de 1941 le llega a Juan Temboury la oportunidad que había deseado durante mucho tiempo. El Instituto Diego de Velázquez dependiente del Consejo Superior de Investigaciones Científicas (CSIC) y heredero del Centro de Estudios Históricos tiene en proyecto actualizar los Catálogos Monumentales de las provincias españolas que se habían publicado en las primeras décadas del siglo XX. Diego Angulo Íñiguez, Director del Instituto, le propone a Temboury que revise el que en 1907 realizó Amador de los Ríos. Temboury se apresura a contestarle afirmativamente ${ }^{32}$ y reconociendo que "llevo unos diez años recogiendo datos, planos y centenares de fotos con miras a hacer, alguna vez, cosa parecida", pero le da a entender que Catálogo inédito de Amador de los Ríos no se puede revisar sino que hacerlo de nuevo. No se anda con paños calientes cuando da su opinión sobre el referido Catálogo:

29 TEMBOURY ÁLVAREZ, J. "Notas sobre la Virgen de la Victoria y su Santuario. Reinterpretación actual de la iglesia de la Victoria", Informes históricos-artísticos de Málaga. Málaga. Caja de Ahorros Provincial de Málaga. 1966. 87-105.

30 SEBASTIÁN LÓPEZ, S. "El Pía Desideria de Hermann Hugo y el Santuario de la Virgen de la Victoria: un ensayo de lectura". Boletín de Arte n 2. Universidad de Málaga. 1981, Málaga. Págs. 932

31 CAMACHO MARTÍNEZ, R. "La emblemática y la mística en el santuario de la Victoria en Málaga" Cuadernos de Arte. Fundación Universitaria. 1986. Madrid.

32 Carta de Juan Temboury a Diego Angulo del 14 de mayo de 1941. Legado Temboury. 
"Conozco bien los enormes misales de Amador de los Ríos, donde casi la totalidad del texto es la huera y ampulosa literatura de su época; todas sus largas páginas podían recogerse en ocho o diez cuartillas y acaso un par de ellas lo que hay personalmente suyo y no tomado de Berlanga, Guillen Robles, Marzo, etc.

Temboury admite la condición de que siga figurando el nombre de Amador de los Ríos como autor, pero impone una serie de condiciones para afrontar el trabajo

"Me parece muy bien si, por motivos sentimentales o de economía, quieren Vds. conservar el nombre de D. Rodrigo al frente de la publicación; pero ello no evita el tener que hacerlo todo de nuevo. Tendría que contar con los datos de su «Guía», con Torres Balbás para cosas musulmanas, con Hernández para los castillos, con Martínez Santaolalla para la prehistoria, con Guerrero Strachan para arquitectura religiosa y con Fernández para la parte de Antequera ${ }^{33}$. De elementos gráficos hay que hacer plantas de muchos edificios, alzados de algunos: muchas fotos nuevas: contar también con el Laboratorio de Arte, con los negativos hechos por Amador de los Ríos (los conserva la familia en Alcalá de Henares) y con los de Orueta.

De modo que Vds. deciden pero siempre a base de que sea sin agobios de tiempo y contando con la colaboración de todos."

En resumen, Temboury estaba dispuesto a quedar en el anonimato sobre la obra en cuestión, pero en lo que no pensaba ceder era en la calidad que debía presidir, cuando se publicase, el Catálogo Monumental de la provincia de Málaga.

Aunque no conocemos la respuesta de Diego Angulo, es de pensar que esta fuese afirmativa, por lo que Temboury se puso a trabajar ${ }^{34}$, con más intensidad

33 De las colaboraciones que Temboury esperaba y deseaba obtener las había de muy distinta factura. Aunque no tenemos constancia de que Temboury hablase sobre el tema con Torres Balbás, es muy posible que lo hiciese porque durante esos años este último realizó publicaciones relacionadas con el Patrimonio de Málaga, así como que tenemos constancia de que le demandó a Temboury información sobre monumentos musulmanes de la provincia como es el Castillo de Antequera o el de Marbella. Cuando Temboury escribe Hernández posiblemente se esté refiriendo al arquitecto Félix Hernández Jiménez (1889-1975). Al manifestar su deseo de que fuese Martínez Santaolalla el que asumiese la parte de arqueología, consideramos que lo que estaba realizando era una labor meramente política (en esa época Julio Martínez era el Comisario Nacional de Excavaciones Arqueológicas y quien lo había nombrado Comisario local de Málaga), ya que sin desmerecer las posibles valías de la persona propuesta, el conocimiento que sobre la arqueología provincial debía poseer su amigo Simeón Giménez Reyna fue sacrificado por Temboury en aras de alguien políticamente más importante. El deseo de que Fernando Guerrero-Strachan Rosado asumiese la arquitectura religiosa debió quedarse sólo en la intención, ya que Guerrero-Strachan falleció en septiembre de ese año. La elección del pintor y cronista de la ciudad José Ma Fernández "para la parte de Antequera", no solo era muy acertada sino que

34 En una visita que realizamos a la Biblioteca Tomás Navarro Tomás, sede donde se encuentran los fondos del Instituto Diego Velázquez, pudimos comprobar que las distintas personas a las que se les 
y con un objetivo concreto: realizar el tan buscado y deseado Catálogo Monumental de la provincia de Málaga

Hasta los años veinte del pasado siglo el centro de la Málaga estaba aún sometido a un urbanismo de ciudad amurallada, su crecimiento se había dado ganándole terrenos al mar o construyendo barrios que de algún modo quedaban aislados por carecer la ciudad de ejes norte-sur y este-oeste que facilitasen la comunicación y el crecimiento. Para realizar el primero de ellos hubo que derribar todo un intricado barrio de estrechas callejuelas denominado «la Alcazabilla» por encontrarse en la falda oeste de las murallas que defendieron en su día el conjunto monumental de la Alcazaba. Con el derribo del barrio Juan Temboury concibió la oportunidad de excavar en los solares que habían quedado libres, porque estaba convencido que en los alrededores de las murallas se podían encontrar importantes restos arqueológicos. Pero los intentos de Temboury siempre resultaron fallidos, la especulación inmobiliaria primaba sobre la búsqueda de Patrimonio. Se fue construyendo en cada uno de los solares de la nueva calle Alcazabilla. En la zona colindante con las murallas árabes solo quedaba un solar donde en los años cuarenta se decidió construir un edificio denominado Palacio de Archivos y Bibliotecas. Temboury intentó de nuevo que ese edificio se construyese en otro lugar, pero como siempre sus gestiones resultaron infructuosas. Si nos atenemos a lo que dice a modo de memoria en un documento que existe en su Legado, aprovechaba por las tardes, cuando se paraba la obra, para bajar y contemplar cómo los cimientos del edificio se estaban construyendo sobre restos arqueológicos e incluso aprovechan algunos de esos restos para que formasen parte de la cimentación. Los años en que esto ocurría no eran propicios para la más mínima protesta, incluso para un colaborador, como en ese momento era Temboury.

Cuando el edificio estaba prácticamente terminado, el Cabildo Municipal asumió la tarea de adecentar el terreno que quedaba delante del edificio en construcción por medio de la creación de un jardín. Se le encargó al arquitecto municipal, Enrique Atencia, el diseño de esos jardines. Atencia era un buen amigo de Juan Temboury y en ese momento estrecho colaborador en varios proyectos, por lo que este último vio la oportunidad de aprovechar la construcción del jardín para hacer un sondeo exploratorio de la zona. A finales del mes de mayo de 1951 Atencia, con el que se encontraba Temboury, da la orden de excavar una zona del terreno en el que al hacerlo a una profundidad de cuatro metros apareció lo que parecía ser una entrada a la Malaca romana.

había encargado la revisión de los Catálogos enviaban a la referida Institución minutas con los gastos de las fotografias que realizaban, de Juan Temboury no encontramos ninguna y además nos consta que no lo hizo. 
La noticia corrió entre la población como la pólvora y con ella las más disparatadas versiones de lo hallado, hasta el punto que cuando el día 14 de junio el diario Sur dio la noticia, Enrique Atencia al ser entrevistado les pide a los curiosos que les dejen espacio para trabajar.

Las excavaciones se ampliaron y con ellas se comenzó a vislumbrar la importancia de lo descubierto. Comenzaron a aparecer en los diarios distintas interpretaciones de lo encontrado y «descubridores potenciales», pero para la generalidad el descubridor era Juan Temboury, siendo tratado poco menos que como un héroe. Cuando se determinó que lo hallado eran parte de un teatro romano se elucubraron múltiples teorías y determinación de su importancia; llegando a calificarlo, antes de ser excavado como de más importancia que el de Mérida. Se comenzó a valorar seriamente la posibilidad de derruir el edificio a punto de terminarse para garantizar la excavación. Pero al final todo quedó en una serpiente de verano. El Gobernador Civil, que no había dado ninguna opinión sobre el tema, el 14 de septiembre vuelve de Madrid de recibir instrucciones y manifiesta:

"No dudo de la importancia del hallazgo arqueológico, pero estimo que todo está muy derruido. En cuanto a ese atrevido rumor de derribar el palacio de ..., me voy a limitar a contestar con una cita que debo al archivero señor Baguenas de una ley romana dictada para Málaga y cuya rúbrica, traducida al castellano dice «Nadie destruya un edificio que no ha de volver a construir». Con esta rúbrica romana fijo yo mi criterio"35.

Esta posición fue reafirmada por el diario oficial del Régimen, Arriba, lo que constituyó la posición oficial de las autoridades y por tanto, aquello que los medios de comunicación que lo habían valorado hasta la exageración lo hallado, cambiaron de opinión: "Se corre el riesgo demasiado probable de no encontrar debajo de él [Casa de la Cultura] otra cosa sino un puñado de piedras carcomidas de mediocre valor decorativo y valor arqueológico de cuarta categoría"36.

En realidad todo se trataba del resultado de una lucha de poderes entre distintas familias del Franquismo y que duraría hasta que en 1957 cuando, en un nuevo cambio de equilibrios, José Luis Arrese fuese nombrado ministro de la vivienda y que consiguiese llevar a su ministerio el control sobre las

35 La cita se está refiriendo al título LXII de la Lex Flavia Malacitana: "R. NE QUIS AEDIFICIA QUAE. RESTITUTURUS NON ERIT. DESTRUAT". RODRIGUEZ DE BERLANGA, M. Estudios sobre los dos bronces encontrados en Málaga a fines de octubre de 1851. Imprenta el Avisador Malagueño. Málaga. 1853.

36 Revista quincenal Acción editada por la C. N. S. de Málaga (Sindicato Vertical), en su número correspondiente al 15 de septiembre. 
excavaciones arqueológicas. Mientras tanto, durante ese periodo un manto de silencio total cubrió lo referente al Teatro Romano. Juan Temboury fue la única persona damnificada por esa lucha entre poderes, con lo que el manto de silencio también lo cubrió a él durante el mismo periodo y más allá. El Temboury del que los medios de comunicación, durante la década anterior, habían solicitado constantemente su colaboración, durante la década de los años cincuenta fue condenado al olvido. Había tenido la mala suerte de encontrarse en medio del fuego cruzado entre dos frentes amigos.

Pero Juan Temboury demostró una vez más que lo importante era la defensa y puesta en valor del Patrimonio. Así, sin ayudas oficiales y sólo con la voluntad casi clandestina de unos pocos, siguió trabajando en las excavaciones y afrontando las críticas y ridiculizaciones que se le hacían.

Si sostenemos que la catalogación del patrimonio Histórico- artístico fue el eje central de toda la labor de Temboury en pro de la cultura, hubo otro elemento muy importante para él, que como un hilo, más tenue pero que nunca se cortó, recorrió un camino paralelo. Nos referimos a su constante defensa, posiblemente la única en Málaga, de la figura y la obra de Pablo Ruiz Picasso. Pocas fueron las ocasiones en la que tuvo la oportunidad de defenderlo desde ya su lejano escrito de 1933 Málaga y el pintor Picasso ${ }^{37}$. Se presentó en 1936 la oportunidad de llevar a Málaga la primera exposición que de la obra de Picasso se hacía en España y que recorrió Barcelona, Madrid y Bilbao, paro las mediocridades y zancadillas impidieron que esta se pudiese ver en su ciudad natal ${ }^{38}$.

Juan Temboury albergaba el íntimo deseo de que alguna vez Málaga fuese la sede del museo que él soñaba: "Hay muchos museos que han tenido la suerte de reunir sus cuadros, pero aquí debía de formarse básica mente la colección Picasso, con representación de la marcha evolutiva de su obra y con sus grandes quiebros de orientación" 39 .

La primera ocasión de contactar con Picasso se la ofreció un sobrino del pintor, Ricardo Huelin. Pero cuando Temboury vislumbró la verdadera oportunidad de hacer realidad su proyecto fue cuando en el mes de octubre de 1953 visitó Málaga el secretario de Picasso, Jaime Sabartés. Aunque oficialmente Sabartés venía a conocer las raíces malagueñas de Picasso,

37 TEMBOURY ÁlVAREZ, J. "Málaga y el pintor Picasso", Revista Málaga nº1. Editada por la Sociedad Económica de Amigos del País de Málaga. Mayo de 1933.

38 SARRIA FERNANDEZ, C. "La exposición que nunca llegó", Revista Isla de Arriarán no XXXIX. Asociación Cultural Isla de Arriaran. 2016. Málaga. Págs. 267-325.

39 Carta de Juan Temboury a Pablo R. Picasso del 26 de mayo de 1953. Museo Picasso Málaga. 
nosotros sostenemos que en el viaje también traía el encargo del maestro de sondear la posibilidad de que fuese en un futuro Málaga la sede donde exponer la enorme cantidad de obras que él había ido acumulando a lo largo del tiempo, deseo que el pintor había manifestado en varias ocasiones. Sabartés, que vino con su esposa, fueron recibidos por Temboury como él acostumbraba a hacerlo, con lo que el matrimonio quedó agradablemente sorprendido. Pero si es cierto que Sabartés venía a sondear el encargo de Picasso, la opinión que se llevó de Málaga no pudo ser más negativa, una ciudad con una economía muy deprimida y con un potencial turístico, como motor de esa economía aun por desarrollar; es de suponer que viniendo desde París, esto supondría casi un viaje hacia tras en el tiempo, incluso después de haber pasado por Barcelona. Esta visión negativa de la ciudad estuvo presente en toda la correspondencia que a partir de ese momento mantuvieron Jaime Sabartés y Juan Temboury. Nosotros mantenemos que a su vez fue el detonante para que Sabartés comenzase a realizar gestiones en Barcelona como posible sede de los fondos picassiano. Pero no todo fue negativo en el viaje del matrimonio Sabartés a Málaga, estos se volvieron con otra Málaga grabada en su retina, la que el secretario de Picasso acostumbraba a denominar en sus cartas como "la Málaga de Temboury". Así en la primera carta que Sabartés le envía a Juan Temboury le escribe: "Quiero decir pues, que conservo intacto el recuerdo de sus milagros o resurrecciones: la Alcazaba, el Palacio Episcopal, La iglesia de la Victoria, el museo..." ${ }^{40}$. En resumen, interpretamos que sólo la actuación de Temboury y su obra hizo que Sabartés, aunque desilusionado, dejase aún una llama, más pequeña de lo deseado, que Temboury logró mantener viva y proyectando hacia el futuro la conexión Picasso-Málaga que fructificó en lo que es hoy el Museo Picasso Málaga y que él no pudo disfrutar. Y todo ello a pesar de las oposiciones, censurar y piedras en el camino que se encontró tanto de las autoridades como de la mediocridad de casi toda la considerada «intelectualidad local».

Existen otros muchos ejemplos del volumen de intervenciones que Temboury realizó en pro de descubrir, preservar, valorar y defender el patrimonio histórico-artístico malagueño. Algunos de ellos tan desconocidos como el haber sido el primero en demostrar la influencia de la pintura flamenca en el barroco andaluz a través del pintor Diego Manrique artista que hasta que Temboury lo estudió era un perfecto desconocido incluso entre los especialistas. O la demostración inapelable de la autoría de Guglielmo della Porta en la obra

40 Carta que Jaime Sabartés a Juan Temboury del 18 de enero de 1954. Museo Picasso Málaga. 
del sepulcro de Arzobispo de Salerno, Luis de Torres, que se encuentra en la Catedral.

La pronta visita de la muerte impidió a Juan Temboury ver culminada su máxima aspiración: la publicación del Catálogo Monumental de la Provincia de Málaga. Pero como en el poema de Kavafis Itaca: "lo importante no es la meta, sino el camino". Y como ejemplo no hay nada que lo demuestre mejor que su archivo, convertido en Legado gracias a la generosidad de su esposa Victoria Villarejo y de sus hijos que lo cedieron a la Diputación Provincial para su organización y custodia. El Legado Temboury se puede considerar el más completo y valioso de la Provincia y, posiblemente, uno de los legados privados más valiosos de España. En resumen, en la labor que a lo largo de la vida realizó Juan Temboury Álvarez se cumplen a rajatabla las tres condiciones que la UNESCO define como indispensables y necesarias para la protección del Patrimonio: $1^{\mathrm{o}}$ "Registros e Inscripciones", $2^{\mathrm{o}}$ "Protección, Salvaguardia y Gestión" y $3^{\circ}$ "Transmisión y Movilización de Apoyos".

Carlos Sarria Fernández

Licenciado en Historia del Arte y Master en Desarrollos Sociales de la Cultura Artística. Ambas titulaciones cursadas en la Universidad de Málaga (UMA) Estudios Avanzados en Humanidades: Historia, Arte, Filosofía y Ciencias de la Antigüedad Facultad de Filosofía y Letras Universidad de Málaga (UMA) https://orcid.org/0000-0002-7835-1949 csarriafernandez@gmail.com 